\title{
Smart Energy Metering System using Android Mobile Application
}

\author{
R.Govindarajan, Research Scholar, SCSVMV University, Enathur, Tamilnadu, India, \\ govind@kanchiuniv.ac.in \\ S.Meikandasivam, Professor \& Head, VIT University, Vellore, Tamilnadu, India, \\ meikandasivams@vit.ac.in \\ R.Malathi, Associate Professor, SCSVMV University, Enathur, Tamilnadu, India, \\ malathinandhini@yahoo.co.in \\ M.Kiranmai, UG Student, SCSVMV University, Enathur, Tamilnadu, India \\ kiranmaimarepalli28@gmail.com
}

\begin{abstract}
In recent years, smart-devices became very popular. This paper presents the smart energy monitoring system using android application. This system is efficient and convenient to achieve the visualization of real time values that are received from the energy meters via NodeMCU module. This application enables the user to control their power usages in the house by knowing about the consumption of power at any time. In this the analog data is converted to digital data with the help of inbuilt NodeMCU and passes it to the Arduino controller. Android based mobile phone itself transmits and receives data using Arduino IDE module, power supply and NodeMCU.
\end{abstract}

Keywords - NodeMCU, GSM, Arduino IDE Module, Android smart phone, smart meter

\section{INTRODUCTION}

These days, there has been an incredible change in clients' inclination in the mobile sector with the quick headways in chip innovation and programming. Most of the individuals are using cell phone for communicating with one another and also it has become a hobby to use smart phone for exploring social media, network services, games, music etc. In a world of exceptionally created nations and developing commercial concerns, power supply assumes a real part. In a cutting edge family, scarcely any gadget runs without power. So the energy consumption and conservation is a vital part of the household [1].

The electricity companies use traditional electric meter for accounting. It is the electromechanical induction watt-hour meter. Its robust technical design is in use for over a century, but is not capable of more than measuring the accumulated amount of consumed energy [2]. The disadvantage of this is that it requires intervention of human where an employee sent by the utility company or the customer himself has to read the meter manually which implies costs and administration effort.

The conventional electric meter, utilized by power organizations for accounting is the electromechanical actuation meter. The electromechanical meter is used only for the collective measure of consuming energy. The disadvantage is that either a worker, sent by the vitality organization or the client himself need to persue the meter physically which infers expenses and organization exertion.

The electricity supply company adopts the electronic meters, i.e. Electronic measurement of energy consumed. These meters have diminished the assembling expenses, enhanced measurement, exactness, precise data and most importantly reduced size. Due to these benefits that go past the customary rotor plate energy meter. The smart meter is identified as AMR and AMI technology [3].

In this paper an application of energy measurement on android platform is developed. This application is an online service that connects to consumer's smart phone via NodeMCU. The proposed Smart metering system measures the power consumed and send data to consumer's smart phone. The main objective behind the development is to develop efficient power measuring application for displaying the data of power consumption on the Android phone. The system was designed to transmit wireless signals directly to the Android Phone via NodeMCU on the Android Platform [4]. The consumers can easily visualize the power consumed because it does not require any mounted monitor.

\section{ANDROID}

In the field of android operating system, the Android 1.0 was the first Android OS, which was commercially released in September 2008.This mobile application development platform was an open source. The collaboration of the 
Google with the Open Handset Alliance designed this Android Platform. The Android SDK has many tools and different APIS, which can use in designing and developing different mobile apps. Android has grown as a main mobile platform because of its updated and software features [5]. The latest version of the Android was Android L API level 21 which was released on 16 June, 2014 and updated on 25 June, 2014 of Android Kit Kat 4.4.4.

Linux is used as the operating system for Android OS. This android OS is used in mobile, smart phone and tablets. The developers can use the full features of the hardware system because it is an open source platform for mobile applications.

The environment of android and the android architecture is software based which has some parts like Linux, OS, number of application frameworks, different libraries, end user applications and more. Figure 1 shows the architecture of android [6].

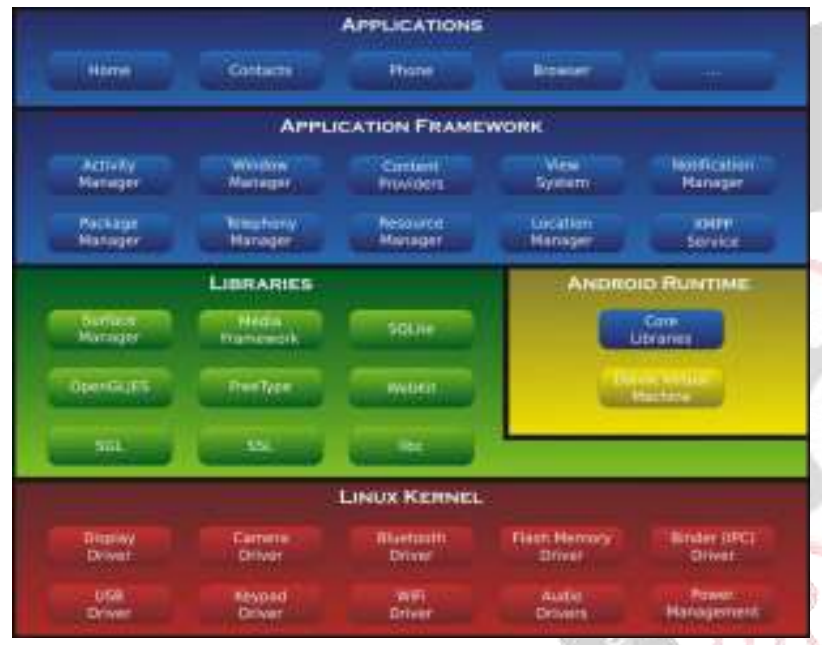

Fig 1: Android Architecture

\section{A. Linux Kernel}

The bottom layer of android architecture consists of Linux (Linux 2.6) having 115 numbers of patches. This system contains basic functions such as managing a number of processes, memory management, managing a number of devices for e.g. camera, keyboard, display etc. It's the duty of the kernel which manages all the resources. Linux is an efficient platform for operations such as networking and also has vast area of device drivers[7].

\section{B Libraries}

Kernel consists of bunch of libraries on the top layer of Linux, which includes open-source like WEB engine, valuable libraries, SQLite database that are helpful for storage and sharing of data application, libraries which are helpful for playing and recording audios and videos and other libraries used for internet security purpose.

\section{Android Runtime}

It is the third part of the android architecture. This platform provides a precious component known as Dalvik Virtual Machine. It is a sort of Java Virtual Machine used for designing and optimizing of Android systems. The Dalvik VM is helpful to provide various resource management such as memory management and multithreading. The DVM makes every application of android to execute in their own process. The Android architecture also consists of libraries which make Android developers to develop android applications with the help of standard Java programming language.

\section{Framework of Application}

This layer gives a lot of high level services to android based application in the form of classes of Java. Developers of applications have permission to make use of the above mentioned services in their designed applications[8-12].

\section{E. Applications}

Top layer consists of all types of Android applications. The users have to write their application to be installed on this layer only. Some of them are like Contact, Books, Browser, Games and many more. Elements of the application are the important components of an Android application.

\section{NODEMCU}

NodeMCU is an open source firmware for which open source prototyping board designs are available. The name "NodeMCU" combines two words "node" and "MCU" (micro-controller unit). Strictly speaking the term "NodeMCU" refers to the firmware rather than the associated development kits.

The firmware as well as the prototyping board designs is open source. The firmware uses the Lua scripting language. The firmware is based on the eLua project and is built on the Espressif Non-OS SDK for ESP8266.

Typically, the prototyping hardware used is a circuit board functioning as alike the dual in-line package which integrates a USB controller with a smaller surface-mounted on it that contains the MCU and antenna. It allows the DIP format used for easy prototyping on breadboards. Initially the design was based on the ESP-12 module of the ESP8266, which is a Wi-Fi SoC integrated with a Tensilica Xtensa LX106 core which is widely used in IoT applications.

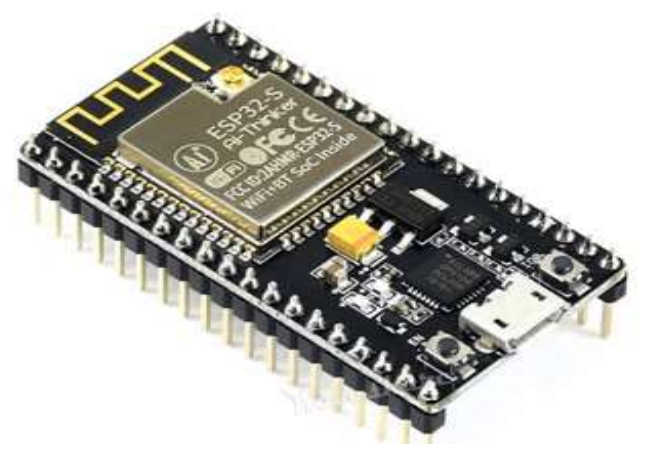

Fig.2: NodeMcu (ESP32 DevKitC Board ) 


\section{SySTEM OVERVIEW}

The block diagram of the system is shown in the following figure: 3 . The power supply circuit supplies power to other components. In this the TXD pin of the Android IDE Module is connected to the RXD pin of NodeMCU and vice--versa [13].

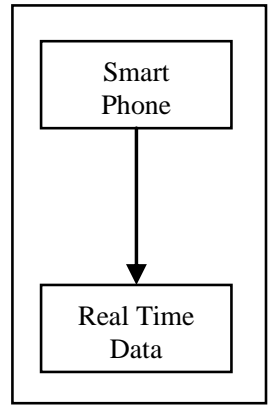

a) Receiver

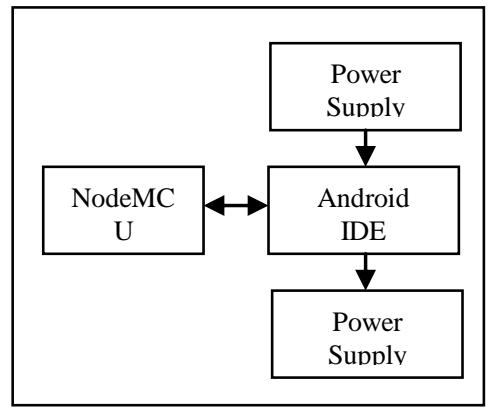

b) Transmitter
Fig 3: System Architecture

The first step is to start the application. Second step describes the communication between the smart meter and the smart phone using NodeMCU. Third step is the user case to read the information about power consumption from smart meter. Figure 4 shows Flow diagram of the application activity.

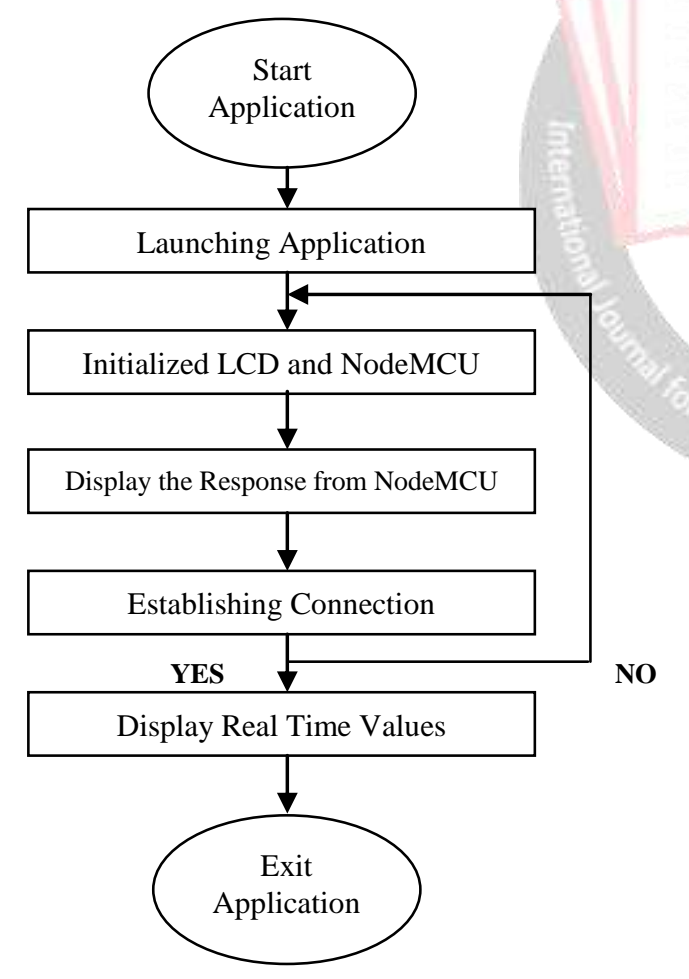

Fig.4: Flow Diagram

\section{SYSTEM IMPLEMENTATION AND RESUlT}

The wireless android application is to be represented in automatic way which provides the useful functionality to display real time power reading from the smart meter. A Communication medium between the smart meter and the Android phone is NodeMCU. Hence the NodeMCU is the major part in the system, which is required to send the real time values to the Blynk Mobile Application. The application code was written in the Embedded $\mathrm{C}$ programming language using Eclipse Integrated Development Environment (IDE) with Android Developer Tools (ADT)[14].

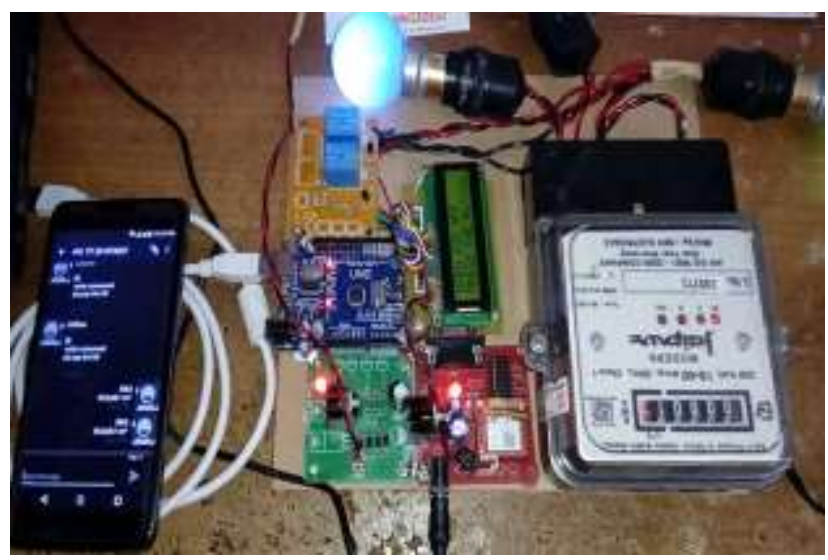

Fig.4: Smart Energy Monitoring system using Android Application

Eclipse is the simplest way to create any component or Android project. The Android application is a User's Interface (UI) to the NodeMCU processor. This application gives the consumer numerous options to calculate power consumed and display the data [15]. Another important file for developing the android application is android manifest. Androidmanifest.xml record is utilized within every android application which is found in the root registry of android undertaking. This will be created naturally when you design an android application. The android manifest.xml document transfers the data of your android application to the android framework before the running the code of application. The androidmanifest.xml document is likewise used to characterize diverse consent, for example, NFC (Near Field Communication), camera access, Bluetooth and so on.

The system hardware is shown in figure-4.which contains the components used in the project such as Arduino IDE Module, power supply, NodeMCU processor and transformer [16,17]. The developed Wireless android application is running on the smart phone which has 4.1.2 jelly bean android operating system. The output of the application is shown below in the form of captured images. Following images are captured by android mobile phone: Figure 5 shows the output report format. 

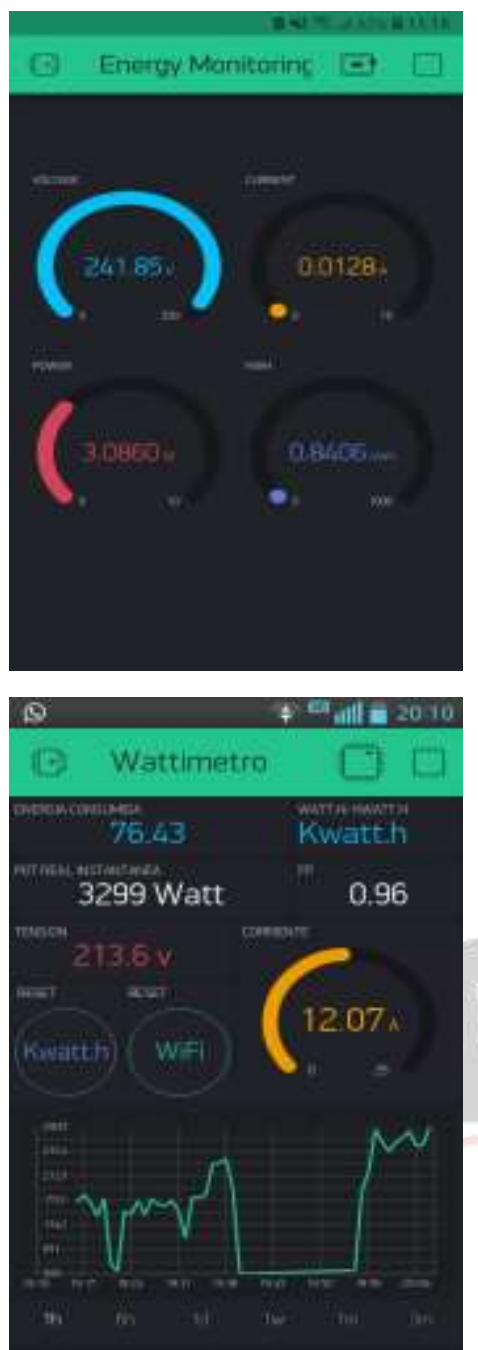

Fig.5: Smart Energy Monitoring system reading appeared in the Android Mobile Phone

\section{Conclusion}

In this paper we design and develop an Android application for power measuring using a wireless plug. This system is designed to monitor the energy consumption and send that data to the smart phone via wireless plug. This application runs on the android based smart phone which supports android OS 4.2.1. This system consists of three main parts which include collection of data, data processing and to display the data in smart phone. Our entire objective is successfully achieved and implemented along with testing. We developed a hardware and software solution for monitoring the power consumption. Some limitations are also present in this system such as low sampling rate and low resolution. After all, we are capable of combining latest mobile technology with the electrical and wireless technology and hence developed a simple and robust system for power utility companies.

\section{REFERENCES}

[1]. Liang, Z. H. A. O., and Wei ZHANG. "Research and Design of Interface Based on Android Technology", Computer Knowledge and Technology, Vol.29 (2009).
[2]. Shi-Cheng, Z. H. A. N. G. "Development and Research of Application Based on Google Android", Computer Knowledge and Technology, Vol. 28 (2009).

[3]. Wagner, Matthias, Benjamin Kuch, Carlos Cabrera, Peter Enoksson, and Arne Sieber. "Android based Body Area Network for the evaluation of medical parameters." In Intelligent Solutions in Embedded Systems (WISES), 2012 Proceedings of the Tenth Workshop on, pp. 33-38. IEEE, 2012.

[4]. Lau, Hon Fai, and Shigeru Yamamoto. "Bayesian online changepoint detection to improve transparency in humanmachine interaction systems." In Decision and Control $(C D C), 2010$ 49th IEEE Conference on, pp. 3572-3577. IEEE, 2010.

[5]. K. Rummler, J. Seipold, E. Lubcke, N. Pachler and G. Attwell, "Mobile Learning: Crossing boundries in convergent environment," Book of abstracts of the conference mobile learning:crossing boundries in convergent, March 21-22, 2011. ISSN 1753-3385.

[6]. G. Hartmann, G. Stead, A. DeGani, "Cross-platform mobivle development" TRIBAL, http://www.mole-project.net, March 2011.

[7]. Ribeiro and A. R. daSilva, "Survey on Cross-Platforms and Languages for Mobile Apps," Eighth International Conference on the Quality of Information and Communications Technology (QUATIC), IEEE Xplore, ISBN 978-1-4673-2345-1, pp. 255-260, 2012.

[8]. R.Govindarajan, Dr.S.Meikandasivam, Dr.D.Vijayakumar, “ Energy Management Techniques in Smart Grid", International Journal of Applied Engineering Research, Volume 10, Number 15, pp.35720- 35724, 2015.

[9]. R.Govindarajan, Dr.S.Meikandasivam, Dr.D.Vijayakumar, "Low Cost Arduino Based Smart Energy Monitoring System Using Internet of Things", Journal of Engineering and Applied Sciences, Volume 14, Issue 01, pp.170-177, January 2019.

[10]. MoSync, "http://www.mosync.com/the company, 2013.

[11]. Darlington Transistor Array, Texas Instruments, http://www.ti.com/lit/ds/symlink/uln2803a.pdf, August, 2013.

[12]. Serial Bluetooth Module, Tiny OS Electronics, http://www.tinyosshop.com/index.php?route=product/produ ct\&product_id=330, 2013.

[13]. Keil vision IDE, http://www.keil.com/uvision/, August 2013.

[14]. R.Govindarajan, Dr.S.Meikandasivam, Dr.D.Vijayakumar, "Cloud Computing Based Smart Energy Monitoring System”, International Journal of Scientific and Technology Research, Volume 08, Issue 10, pp. 886-890, October 2019.

[15]. AT89c51 8 bit Microcontroller, ATMEL Corporations,http://www.atmel.com/images/doc0265.pdf, August 2013

[16]. J. Haartsen, "Bluetooth-The universal radio interface for ad hoc, wireless connectivity", Ericsson Review No. 3, pp. 110117, 1998.

[17]. P. Singh P, S. Sharma, S. Agrawal, "Study of Bluetooth wireless technology using java", Indian Journal of computer Science and Engineering, Vol. 2, No. 3, pp. 295-307, 2011. 